\title{
O IMPACTO DA REFORMA UNIVERSTTÁRIA NAS UES BAIANAS
}

\section{The Impact of the University Reformation in the Bahian UES}

\author{
Ronalda Barreto Silva ${ }^{1}$ \\ Wagner Duarte José ${ }^{2}$
}

\section{Resumo}

Trinta e oito anos após a Reforma de 68, temos, na ordem do dia, uma nova reforma universitária em um govemo popular. Algumas questões devem ser postas a fim de problematizarmos a discussão da proposta de reforma atual. No ano de 1961, Álvaro Vieira Pinto escreveu o livro A Questão da Universidade, publicado pela UNE, no qual afirmava que, com a mudança dos alicerces da realidade social, a classe dominante não podia mais contar tranqüilamente com a universidade como foco das concepções alienadas que favoreciam o seu domínio, como também a universidade começava a ser assediada por um exército popular, cujas intenções eram diversas dos diminutos e requintados alunos selecionados que a procuravam no passado. Os novos postulantes queriam a universidade para adquirir conhecimentos que os qualificassem para o trabalho futuro, útil, para a participação política, para modificar a estrutura social antiga e injusta, substituindo-a por outra humana e livre. Nesse bojo, outra questão apontada é importante: sacudir o jugo das pressões imperialistas que entravavam o país. Essas foram idéias que levaram os estudantes e setores progressistas da sociedade brasileira a desejarem a reforma da universidade. Partindo da concepção colocada por Pinto (1994) naquele momento, de que a classe dominante solicita da universidade acima de tudo as idéias que justifiquem o seu poderio, questionamos: quais os interesses subjacentes à reforma universitária que, desta vez, não está vindo dos anseios populares? Como estão postas, hoje, as pressões imperialistas, cujo jugo queria os estudantes erradicar na década de 60 ?

Palavras-chave: Política educacional; Reforma universitária.

1 Prof. ${ }^{\text {a }}$ Dr. ${ }^{\text {a }}$ Adjunta da Universidade do Estado da Bahia-UNEB, Doutora em História da Educação pela UNICAMP. E-mail: ronalda barreto@uol.com.br

2 Prof. Titular da Universidade Estadual de Santa Cruz-UESC, Doutor em Física pela USP/SP. 


\section{Abstract}

Today, 38 years after the Reformation of 68, we have in the order of the day, a new university reform in a popular govemment. Some questions must be ece of fishes in order to problematizarmos the quarrel of the proposal of current reform. In the year of 1961 Alvaro Vieira Young chicken the Question of the University, published wrote the book for JOINS, in which it affirmed that, with the change of the foundations of the social reality, the ruling class could not more count calmly on the university as focus of the mentally ill conceptions that favored its domain, as also the university started to be assediada by a popular army, whose intentions diverse of miniature and were requintados pupils selected that they looked for in the past. The new petitioners wanted the university to acquire knowledge that characterized them for the future, useful work, for the participation politics, to modify the old and unjust social structure, substituting it for another human being and exempt. In this bulge, another pointed question is important: to shake the yoke of the imperialistas pressures that entravavam the country. These had been ideas that had taken the students and progressive sectors of the Brazilian society to desire the reform of the university. Leaving of conception placed for Young chicken (1994) in that moment, of that the ruling class requests of the university above of everything the ideas that justify its power, questions: which the underlying interests to the university reform that, of this time, is not come of the popular yeamings? How they are ece of fishes, today, the imperialistas pressures, whose yoke wanted the students to eradicate in the decade of 60 ?

Keywords: Educational politics; The university reformation.

As universidades brasileiras estão sendo reformadas em função de atender, paulatinamente, à perspectiva da mercantilização da educação. Essas reformas necessitam, para serem implementadas, de administrações centralizadas e heterônomas. Portanto, nos últimos anos, efetivou-se um retrocesso na democracia interna das universidades brasileiras, o que tem uma implicação direta na possibilidade de reafirmá-la enquanto bem público.

O processo de Reforma Universitária foi inaugurado, no nosso entendimento, com a proposta de Reforma do Estado do $\mathrm{MARE}^{3}$. Esta última está fundamentada no discurso do controle social, da parceria público-privado, do público não-estatal e de uma administração gerencial. A perspectiva gerencial tem causado impacto nos aspectos acadêmicos das administrações universitárias.

O estudo de Silva Jr. e Sguissardi (1999) analisa as novas faces do ensino superior e suas relações, entre outros fatores, com a reestruturação do Estado, buscando compreender as novas configurações que vêm assumindo como

3 Ministério da Administração Federal e da Reforma do Estado. 
resposta a necessidades históricas e/ ou ideológicas. Do ponto de vista da estratégia e das ações governamentais para a reconfiguração do Estado - as quais acompanham as transformações na base econômica com a transição do regime de acumulação fordista para o regime de acumulação flexível e a crise do Estado de Bem-Estar - , os autores procuram verificar quais são as idéias centrais dessa reforma e suas principais propostas no âmbito do MARE e do MEC.

O MARE propôs uma série de programas de ação a fim de consolidar o ajuste fiscal, modernizar ou aumentar a eficiência do serviço público e que, segundo o titular da pasta, Ministro Bresser Pereira, seria uma imposição decorrente do processo de globalização que reduziu a autonomia dos Estados na formulação e implementação de políticas e da crise do Estado, iniciada nos anos 70. A questão da modernização ou do aumento da eficiência, na administração pública, seria, para o Ministro, segundo os autores, resultado de um complexo projeto de reforma, que vise a um só tempo o fortalecimento da administração pública direta - núcleo estratégico do Estado - e a descentralização da administração pública com a implantação de 'agências executivas' e de 'organizações sociais' controladas por contratos de gestão (p. 28, grifo nosso).

As premissas fundamentais para as propostas de reforma do aparelho administrativo do Estado partem do entendimento de que o Estado moderno, social-democrata, seria composto de duas esferas: um núcleo burocrático, voltado para a consecução das funções exclusivas do Estado, e um setor de serviços sociais e de obras de infra-estrutura. O setor de serviços sociais faria parte do Estado, mas não seria governo, e suas funções existiriam no setor privado e no setor público não-estatal, entre os quais estariam as universidades, as escolas técnicas, os centros de pesquisa, os hospitais e os museus, os quais seriam transformados em organizações sociais.

É muito clara, nas propostas do MARE, a transferência das responsabilidades do Estado para o setor privado, no sentido estrito do termo e no denominado público não-estatal, como podemos perceber pelo significado que assume a reforma do Estado para os mentores do Plano Diretor da Reforma do Estado de 1995, de acordo com o trecho citado:

(...) transferir para o setor privado as atividades que podem ser controladas pelo mercado. Daí a generalização dos processos de privatização de empresas estatais. Neste plano, entretanto, salientaremos um outro processo tão importante quanto, e que, entretanto não está tão claro: a descentralização para o setor público não-estatal da execução de serviços que não envolvem o exercício do poder de Estado, mas devem ser subsidiados pelo Estado, como é o caso dos serviços de educação, saúde, cultura e pesquisa científica. (SILVA Jr; SGUISSARDI, 1999, p. 40). 
Na opinião dos autores, o Estado reduziria seu papel de prestador direto de serviços, mas manteria o papel de regulador, provedor e promotor desses serviços, entre os quais os de educação e saúde. Os autores ressaltam, ainda, as formas de propriedade contidas nesse documento que, ao lado da propriedade estatal e da propriedade privada, define a propriedade pública não-estatal:

Ela seria constituída pelas organizações sem fins lucrativos, que não seriam propriedade de nenhum indivíduo ou grupo e estariam orientadas diretamente para 0 atendimento do interesse público. Esta forma de propriedade seria a mais adequada para o setor das atividades não-exclusivas ou competitivas do Estado. Não seria adequada a propriedade estatal, porque aí não se exerceria o poder de Estado; não seria a propriedade privada, porque se trataria de um tipo de serviço, por definição, subsidiado. A propriedade pública não-estatal tornaria mais fácil e direto o controle social, pela participação nos conselhos de administração dos diversos segmentos envolvidos, ao mesmo tempo em que favorece a parceria entre sociedade e Estado (BRASIL, 1995, p. 53 apud SILVA Jr.; SGUISSARDI, 1999, p. 42).

Afirma Pereira e Grau (1999) que esse seria o Estado social-liberal por meio do qual proteger-se-iam os direitos sociais, seria mais eficiente ao introduzir a competição e a flexibilidade na provisão desses serviços e mais democrático pelo fato de suas atividades submeterem-se diretamente ao controle social. Os autores afirmam que o objetivo principal seria conduzir a uma administração com critérios gerenciais de eficiência e a participação cidadã mediante controle social.

Na análise das universidades, um aspecto importante a destacar é a ênfase que os autores dão à necessidade de transparência efetiva da coisa pública e de sua gestão contra a violação dos direitos públicos e a privatização da res publica subordinadas ao controle social para a proteção dos direitos públicos. Além do controle social e de procedimentos, vale ressaltar a indicação de controle por competição administrada ou quase mercado e controle por resultados. A competição por recursos e a centralidade nos resultados dão a tônica nos procedimentos das instituições universitárias.

Está posto, portanto, a gênese da parceria público-privado, não apenas no âmbito da universidade ou da educação, mas em todo o setor social.

Como se encontra a questão das relações imperialistas com as agências encarregadas do ajuste estrutural nos países em desenvolvimento? A principal agência para a imposição de políticas sociais, o Banco Mundial, utiliza-se de metodologias economicistas para responder e formular questões próprias do âmbito da cultura e da política e tenta adequar a realidade educativa ao modelo econômico, estabelecendo uma correlação entre "sistema educativo e 
sistema de mercado, entre escola e empresa, entre pais e consumidores de serviços, entre relações pedagógicas e relações de insumo-produto, entre aprendizagem e produto", exaltando a superioridade do mercado na coordenação da atividade humana (CORAGGIO apud De TOMMASI, 1996, p. 102).

A concepção de universidade daí decorrente desvirtua o seu histórico papel de produção do conhecimento "desinteressado" e de formação; de análise e crítica das questões sociais mais relevantes, absorvendo, na íntegra, o discurso neoliberal em torno da eficiência e produtividade. Portanto, segundo Chauí (2000), resulta numa concepção de crescimento que não implica num efetivo desenvolvimento da instituição universitária, dado que coloca uma lacuna entre as pesquisas produzidas, o ensino e a extensão.

Nesse emaranhado em que a universidade se encontra, o movimento docente e o movimento estudantil se debatem com alguns conceitos que devem ser aqui ressaltados, os quais dão sustentação e legitimação ao processo de discussão da Reforma Universitária atual. Podemos destacar os conceitos de autonomia, qualidade e avaliação.

Chauí (2003) afirma que, pelo sistema de avaliação educacional, a qualidade da educação é medida pela sua eficiência em atender às demandas do Mercado, ao modelo de acumulação e de transferência de conhecimentos para a estrutura econômica. Essa retórica se dá em relação aos resultados que se verificam no rendimento escolar, julgado a partir dos objetivos e metas propostos pela escola, sem questionar a validade e o sentido do que se ensina, do que se produz.

Assim sendo, o ensino superior sofre mudanças na sua identidade e no projeto de desenvolvimento institucional das universidades públicas, com o agravamento da sua situação financeira, que as levam a cuidar dos problemas emergenciais de manutenção em detrimento da consolidação da identidade institucional e do projeto de desenvolvimento de cada uma. O sistema de avaliação estabelece metas e indicadores de desempenho, numa associação direta entre universidade-empresa, na perspectiva não só de atender diretamente ao mercado, mas na introjeção de valores do mercado. As metas visam quantificar a produção docente, a aprendizagem dos estudantes, meios pelos quais se avalia (mensura) a produção acadêmica.

Afirma Chauí (2003) que, quando a Reforma do Estado transforma a educação de direito em serviço e percebe a universidade como prestadora de serviço, confere um sentido bastante determinado à idéia de autonomia universitária, introduz o vocabulário neoliberal para pensar o trabalho universitário, como transparece no uso de expressões como "qualidade universitária", "avaliação universitária" e "flexibilização da universidade".

Durante a ditadura, ressalta, uma das bandeiras de luta das universidades públicas foi pela autonomia, isto é, para que as decisões universitárias 
fossem tomadas pelas próprias universidades em seus órgãos colegiados, visava assegurar critérios acadêmicos para a vida acadêmica e independência para definir a relação com o Estado e com a sociedade.

Ao ser transformada numa organização administrada, segundo valores de mercado, a universidade pública perde a idéia e a prática da autonomia, pois esta se reduz à gestão de receitas e despesas, de acordo com metas e indicadores de desempenho. A "autonomia" preconizada se dá no sentido de a universidade captar recursos, fazendo parcerias com as empresas privadas, submetendo-se aos seus interesses em vez de ter sua sustentabilidade garantida integralmente pelos recursos públicos, o que representa, em algum nível, nuances da privatização.

A universidade é uma instituição social, científica e educativa, cuja identidade está fundada em princípios, valores, regras e formas de organização que lhe são inerentes. Seu reconhecimento e sua legitimidade social vinculam-se, historicamente, à sua capacidade autônoma de lidar com as idéias, buscar 0 saber, descobrir e inventar o conhecimento. Nesse processo, ela interroga, reflete, critica, cria e forma, exercendo papel fundamental no avanço e na consolidação da democracia, que implica compromisso com a luta pela democratização dos meios de produção da vida humana (CATANI; OLVEIRA, 2000, p.186).

Quando a universidade abre mão dessa identidade histórica, corre 0 risco de servir a propósitos de reprodução do poder e das estruturas existentes e não à sua transformação. Com isso, ela nega e compromete sua existência, na medida em que perde a sua autonomia, ganha uniformidade e subordinase aos interesses diretos do Estado e/ ou do mercado.

A autonomia, hoje, está associada à qualidade das universidades, definida como competência e excelência cujo critério é o "atendimento às necessidades de modernização da economia e desenvolvimento social" e é medida pela produtividade, orientada por três critérios: quanto uma universidade produz, em quanto tempo produz e qual o custo do que produz. Os critérios de produtividade são: quantidade, tempo e custo, que definirão os contratos de gestão. Os critérios de produtividade não indagam: o que se produz, como se produz, para que ou para quem se produz, mas opera uma inversão tipicamente ideológica da qualidade em quantidade(CHAUÍ, 2000, p. 216).

É importante chamar a atenção para o significado que o conceito de qualidade toma nas orientações dos organismos internacionais fomentadores de políticas educacionais, como o Banco Mundial. Podemos, por exemplo, questionar o sentido em que se dá o aproveitamento e o desempenho escolar, que definem a qualidade da educação para o referido organismo. 
Na perspectiva do Banco Mundial, a qualidade da universidade é medida pela sua eficiência em atender às demandas do mercado, ao modelo de produção e de transferência de conhecimentos para a estrutura econômica. Entretanto, a universidade é o lugar em que são produzidos os agentes e os conhecimentos que se transformam em capital, é local de confronto ideológico e disputa política.

Na medida em que o Estado reduz a sua participação como agente central na alocação dos recursos destinados ao financiamento dos serviços educacionais, transferindo essa responsabilidade aos próprios indivíduos, às famílias ou às empresas, uma das alternativas de sobrevivência da universidade está na captação de recursos, mediante a paulatina cobrança de serviços prestados à sociedade. Esta é uma questão extremamente polêmica, que apresenta duas faces: de um lado, a denominada privatização interna, que subjaz àquela cobrança, destinada a suprir a carência dos parcos recursos públicos que são disponíveis à universidade. De outro lado, a falta de garantia da qualidade almejada desses serviços. Ao contrário dos discursos defensores, essa proposta favorece o sucateamento da universidade, mediante a progressiva omissão do governo em termos orçamentários.

Em que pese as denúncias e greves realizadas pelos movimentos docente e estudantil, as UES baianas vêm sendo alvo da política de desobrigação estatal há pelo menos seis anos, conforme destacam a tabela I e o quadro I abaixo. Em 1998, o Estado aplicou recursos da ordem de R\$ 140,4 milhões nas universidades estaduais, equivalentes a 4,2\% da Receita de Impostos Líquida do Estado, também denominada Receita Tributária Líquida (RTL) ${ }^{4}$.

\section{Tabela I. Orçamentos e cotas das universidades (R\$ milhões)}

\begin{tabular}{|l|r|r|r|r|r|r|r|}
\hline & 1998 & \multicolumn{1}{c|}{1999} & \multicolumn{1}{c|}{2000} & \multicolumn{1}{c|}{2001} & \multicolumn{1}{c|}{2002} & \multicolumn{1}{c|}{2003} & $2004 *$ \\
\hline EOU & 140,4 & 152,9 & 177,8 & 190,6 & 224,6 & 245,1 & 250,6 \\
RTL & $3.340,2$ & $3.704,7$ & $4.472,9$ & $5.077,7$ & $6.087,1$ & $6.767,0$ & $7.584,7$ \\
\% cota & 4,2 & 4,1 & 4,0 & 3,8 & 3,7 & 3,6 & 3,3 \\
\hline
\end{tabular}

Fonte: Diretoria de Orçamento (UESC) e Tribunal de Contas do Estado. * Orçamento aprovado.

4 A Receita Tributária Líquida (RTL) está regulamentada no artigo 212 da Constituição Federal, sendo operacionalmente composta da receita tributária estadual (RTE) somada às receitas provenientes de transferências constitucionais (RTC) legais, inclusive da União, e descontada a transferência constitucional que o Estado deve fazer aos Municípios (TCM), ou seja, RTL=RTE+RTC-TCM. Feito este cálculo, o dispositivo constitucional determina que o Estado deve aplicar, no mínimo, 25\% da RTL em gastos com Educação. 
A diminuição em 0,6 pontos percentuais ao longo dos cinco anos seguintes fez com que a execução orçamentária das universidades (EOU) ficasse reduzida a 3,6\% em 2003 sem que o governo sequer buscasse cumprir o compromisso firmado em 2000 de manter a cota em 3,82\%.

\section{Quadro I. Evolução da RTL, e ou e cota relativas a 1998}

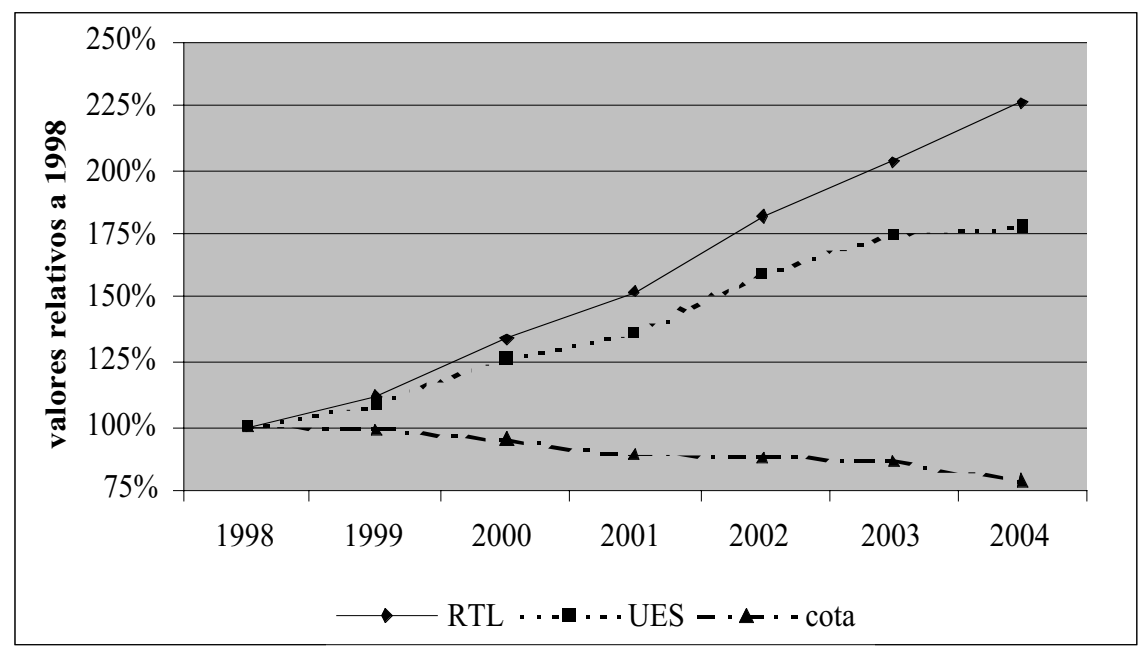

Frente à crise instalada nas universidades, o governo chegou a anunciar para 2004 um aumento da cota para 4,31\%, porém, confinou as universidades na previsão orçamentária de apenas de 3,3\% da Receita de Impostos Ĺquida, ou cerca de $\mathrm{R} \$ 250$ milhões. Não obstante a postura autoritária e desdenhosa, delegou para sua Secretária de Educação $0^{5}$ a tarefa de cobrar do Fórum de Reitores a contenção de gastos das universidades, a quem coube elaborar um plano emergencial de sustentabilidade das universidades. Supomos que quaisquer alterações concretas deverão ocorrer após a finalização da reforma universitária no plano federal.

Nessa perspectiva, a autonomia universitária entra em choque direto com um sistema de avaliação produtivista, que quantifica a produção acadêmica e tem resultado em ampliação ilimitada dos projetos de venda de serviços, que favorece a grupos privados instalados nos espaços de poder interno, reproduzindo o patrimonialismo, o clientelismo, a centralização administrativa, que caracterizam a relação com o setor público estatal, estabelecendo 0 avanço do privado sobre o público. Esse processo, associado ao arrocho salarial, tem gerado um setor de excluídos da participação política autônoma no

5 Ex-reitora da Universidade Estadual de Feira de Santana-UEFS e atual membro da Câmara de Ensino Superior do Conselho Nacional de Educação. 
interior da universidade, provocado pela necessidade real de sobrevivência, o que leva os indivíduos a viverem à mercê dos dirigentes universitários, que se colocam como verdadeiros patrões.

Para se ter um exemplo, enquanto em 1998 o piso salarial da categoria docente era de $\mathrm{R} \$ 280,00$, o que correspondia a 2,2 salánios mínimos da época (que era de $R \$ 130,00)$, hoje o piso dos docentes universitários é de apenas $R \$ 372,88$, que corresponde a 1,4 salário mínimo. Mesmo com as gratificações estabelecidas nos últimos dez anos, seria preciso aumentar em 133\% o vencimento-base dos docentes para se recuperar o poder aquisitivo de novembro de 1990. De outro lado, o número crescente de docentes resultou na ampliação do quadro de efetivos em 2003 e no aumento relativo das despesas de pessoal, que passou de $61,5 \%$ de comprometimento da execução orçamentária das universidades em 1998 para 75,1\% no orçamento de 2004.

Ao mesmo tempo, as despesas de manutenção vêm crescendo, motivadas pela expansão das universidades e pelos aumentos nas tarifas públicas e nos preços dos serviços terceirizados, enquanto as despesas com obras oscilam com tendência de redução nos últimos anos em relação aos primeiros. Nas atividades finalísticas da universidade (projetos), verifica-se a redução orçamentária de maneira vertiginosa a partir de 2001 (28,2 milhões), caindo praticamente, no orçamento de 2004, ao mesmo patamar absoluto do ano de 1998 (20 milhões). O exposto evidencia a intenção em reduzir os gastos em educação superior ao patamar do Estado Mínimo, qual seja de manutenção e regulação da estrutura pública. $\mathrm{O}$ quadro abaixo explicita o impacto orçamentánio destes gastos em termos percentuais na execução orçamentária das universidades ao longo dos anos.

\section{Quadro II. Impacto orçamentário de manutenção, projetos e obras}

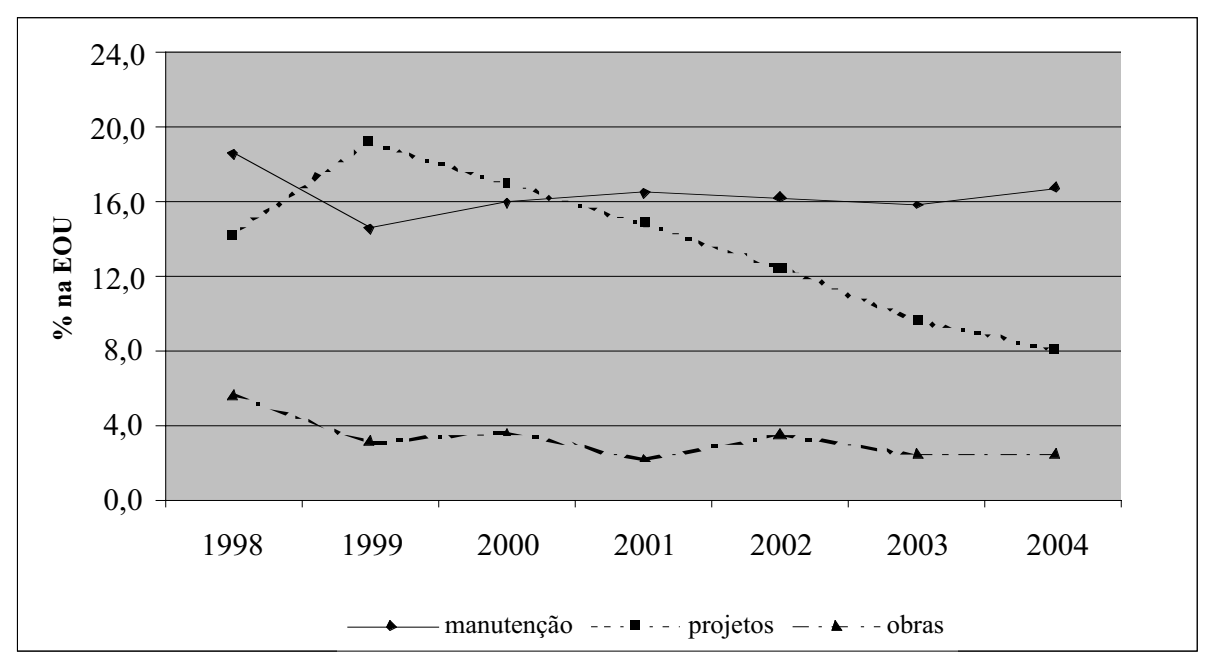


São perceptíveis os esforços empenhados pelas universidades para equilibrar as despesas de manutenção em torno de $16 \%$ do orçamento nos últimos cinco anos. Porém, o setor de obras não acompanha o crescimento das universidades, acarretando à insuficiência de salas de aulas, muitas vezes improvisadas, a falta de salas de professores, a carência total de espaços coletivos para alunos e funcionários, e a necessidade urgente de construção de prédios para acomodarem novos cursos, laboratórios, docentes, etc.

É indiscutível a importância das UES baianas, principalmente no interior, como instrumentos estratégicos para o desenvolvimento socioeconômico do Estado da Bahia, pois elas vêm cumprindo importante papel social na formação das novas gerações e na promoção dos níveis educacionais, sociais, culturais e econômicos das comunidades atingidas. Atualmente, atendem a centenas de municípios, em torno da localização de suas unidades, superando em muito o atendimento registrado em 1998. Infelizmente, amargamos a tristeza de testemunhar o quanto esse potencial tem sido subaproveitado.

As considerações expostas acima definem o sentido da autonomia plena atribuído pelas políticas educacionais, resultando na criação de bolsões de riqueza em contraposição a bolsões de miséria no interior da Universidades, dado que não há uma participação ampla nas definições de prioridades, planejamento, muito menos na fiscalização dos recursos captados.

Assim, as universidades estaduais sofrem, com maior rapidez, a implantação da nova cultura universitária pretendida e em processo nas universidades federais, decorrente de serem mais facilmente flexibilizadas por serem recentes e possuírem uma proximidade maior com os governantes estaduais, os quais interferem com freqüência nos seus destinos. Questiona-se, portanto, o controle social sobre a parceria público-privado. É visível que o processo é de privatização e não de publicização, segundo discurso do MARE. É o caso das estaduais da Bahia, um dos estados que mais sofre intervenção do Banco Mundial, pois todos os grandes projetos educacionais são financiados por esta agência.

O nosso estado teve, ao longo da sua história, governos autoritários, o que tem permitido a experimentação de medidas autoritárias, transformando o estado em um laboratório de políticas públicas a exemplo de ter inaugurado a desconto dos inativos, a gratificação como complemento do salário dos professores ${ }^{6}$. As universidades estaduais da Bahia vivenciam uma centralização administrativa, como aqui referido, que se repete em todas as atividades acadêmicas, esvaziando-as de conteúdos que possibilitem o seu desenvolvimento institucional, condenando-as a transformarem-se em organizações que

6 Anteriores à GED (Gratificação de Estímulo à Docência) e a GID (Gratificação de Incentivo à Docência), implantadas pelo MEC a partir de 1998. 
se limitam a gerenciar contratos de gestão, cujos recursos captados não são destinados sequer à sua manutenção, mesmo frente às atuais dificuldades dessa ordem.

A falta de um planejamento a médio e longo prazo tem dado lugar a políticas de curto alcance, tanto por interesses políticos quanto por interesses do mercado, ferindo constantemente a autonomia universitária. Isso se revela na escolha de seus dirigentes ${ }^{7}$, na interferência de interesses externos e particulares nas decisões internas, na definição de sua expansão e manutenção, com implicações na sua qualidade.

A submissão aos ditames políticos tem o fim de proporcionar lucros financeiros e políticos, muitas vezes com a aquiescência dos Conselhos Superiores. É importante chamar a atenção para o fato de que os referidos Conselhos são desrespeitados na sua dinâmica de funcionamento, constantemente atropelada por longas pautas sem o prévio conhecimento dos conselheiros para o devido aprofundamento das discussões nos Departamentos e, também, para ausência da representação do movimento docente que apenas acompanha as reuniões, sem direito a voto e com voz limitada ${ }^{8}$.

Além da centralização administrativa, o autoritarismo das administrações das nossas universidades é agravado pela falta de transparência, pela falta de critérios claros que fundamentem as decisões pedagógicas, administrativas e financeiras, pela sonegação de informações aos membros da comunidade acadêmica e aos órgãos representativos dos três segmentos.

No momento em que o país volta-se para a discussão da proposta "Universidade para Todos", a Bahia possui projeto semelhante desde 2003, denominado "Faz Universitário", 9 com compra de vagas nas IES particulares. Mais uma vez a Bahia antecipa-se ao Governo Federal e experimenta um projeto a ser adotado para todo o Brasil. Infelizmente, a perspectiva da parceria público-privado, do público não-estatal, não tem resultado em maior democratização dessas universidades, tampouco tem lhes dado condições para maior desenvolvimento acadêmico e intervenções mais significativas no estado. Não é demais enfatizar que o privado avança sobre o público, fazendo valer interesses particularizados.

7 O resultado das últimas eleições da UESB e UESB não foi integralmente respeitado no que concerne à escolha de reitor e de vice-reitor que não fazem parte do grupo político no poder.

8 Imposição da Lei n. $\underline{0}$ 7176/97 que modificou a estrutura das UES baianas, tendo como principais aspectos: reformulou o CONSU e CONSEPE, retirando a representação docente e atribuindo-lhe um caráter técnico; substituiu a eleição direta para reitor e vice-reitor por uma lista tríplice, especificando pesos para o colégio eleitoral de $70 \%$ para docentes, $15 \%$ para servidores técnico-administrativos e 15\% para estudantes; e permitiu a reeleição de reitor e vice-reitor.

9 Uma de suas etapas tem a denominação de "Universidade para Todos". 


\section{Referências}

CHAUÍ, Marilena. A universidade operacional. Disponível em: http:// www.mec.gov.br/portal. Acessado em: 26 maio 2004.

. A universidade em ruínas. In: TRINDADE, Hélgio (Org.). Universidade em ruínas: na república dos professores. Petrópolis: Vozes, 2000.

CATANI, Afrânio M.; OLIVEIRA, João F. de (orgs.). Universidade pública no Brasil: identidade e projeto institucional em questão. In: TRINDADE, Hélgio (Org.). Universidade em ruínas: na república dos professores. Petrópolis: Vozes, 2000.

CORAGGIO, José Luis. Propostas do Banco Mundial para a Educação: sentido oculto ou problemas de concepção? In: DE TOMMASI, L et al. (orgs.). O Banco Mundial e as políticas educacionais. São Paulo: Cortez, 1998.

PEREIRA, Luiz Carlos Bresser; GRAU, Nuria Cunill (Org.). O Público nãoestatal na reforma do Estado. Rio de Janeiro: Editora Fundação Getúlio Vargas, 1999.

PINTO, Álvaro Vieira. A questão da universidade. 2. ed. São Paulo: Cortez, 1994.

SILVA Jr., João José dos Reis; SGUISSARDI, Valdemar. Novas faces da educação superior no Brasil: Reformas do Estado e Mudanças na Produção. Bragança Paulista, EDUSF, 1999.

Recebido: 12 de dezembro de 2006 Aprovado: 12 de fevereiro de 2007 